\title{
"H.O.P.E." Hold On Pain Ends: Effects of Reminiscence Therapy on Depression for Elderly with Alzheimer's Disease
}

\author{
Azliyana Azizan¹, Asilah Anum², Noor Amiera Alias² \\ ${ }^{1}$ Department of Physiotherapy, ${ }^{2}$ Department of Occupational Therapy, Faculty of Health Sciences, \\ Universiti Teknologi MARA, Puncak Alam, 42300, Malaysia \\ azliyana9338@.uitm.edu.my, asilahrustami@gmail.com, nooramiera@.uitm.edu.my
}

Tel :+6010-4591591

\begin{abstract}
Elderly with Alzheimer's disease may experience various adverse effects on physical and psychological functions, especially depression level. Effective intervention may reduce depressive symptoms. Therefore, the current study aims to investigate the effect of individualized reminiscence therapy on depression levels among the elderly with Alzheimer's disease. The findings showed that individualized-reminiscence therapy significantly affects the elderly with Alzheimer's depression level. In conclusion, reminiscence was beneficial through stressful life changes, reduce depressive symptoms, improving life satisfaction and having a better quality of life among the elderly with Alzheimer's disease.
\end{abstract}

Keywords: Alzheimer's disease; Depression; Reminiscence therapy

eISSN: 2398-4287 @ 2019. The Authors. Published for AMER ABRA cE-Bs by e-International Publishing House, Ltd., UK. This is an open access article under the CC BYNC-ND license (http://creativecommons.org/licenses/by-nc-nd/4.0/). Peer-review under responsibility of AMER (Association of Malaysian Environment-Behaviour Researchers), ABRA (Association of Behavioural Researchers on Asians) and cE-Bs (Centre for Environment-Behaviour Studies), Faculty of Architecture, Planning \& Surveying, Universiti Teknologi MARA, Malaysia.

DOI: https://doi.org/10.21834/e-bpj.v4i12.1902

\subsection{Introduction}

There is an increase in population for people aged 60 years and above in most of the developing countries globally. The number of people who are dependent on care will increase from 101 million in 2010 to 277 million by 2050 (Siverova \& Radka Buzgova, 2018). It was expected that 131.5 million of the population will have dementia specifically Alzheimer's disease in 2050 . In Malaysia, the community will increase from $0.126 \%$ to $0.454 \%$ in 2020 and 2050, respectively (Nuri et al., 2017). This phenomenon undoubtedly impacts the countries as it indicates that the high prevalence of Alzheimer's among the elderly may increase the need for healthcare services, burden towards family members, and mortality.

Increased age is accompanied by an increased risk of physical and psychological problems among the elderly population, such as reduced muscle strength, balance and high risk of falls, which can lead to mortality. One of the outstanding psychological issues among the elderly with Alzheimer's is depression. Depression or other mental health problems can give harmful effects on the individual and societies. Depression presents a disorder that was commonly misdiagnosed or undiagnosed experienced by the population of the elderly with Alzheimer's (Sharif, Mansouri, Jahanbin \& Zare, 2010).

There are several treatments to reduce depression among the elderly with Alzheimer's which are pharmacologic and nonpharmacologic. Depression is commonly treated using medication like anti-depressants for quite some time, but this has proven to give side effects (Kikuchi, Uchida, Suzuki, Watanabe \& Kashima, 2011). So, as a strategy to prevent uncontrolled use of drugs and their side-effects, several non-pharmacologic methods offer various significant benefits in terms of decreasing depression and improving the quality of life in the elderly with Alzheimer's disease.

eISSN: 2398-4287 @ 2019. The Authors. Published for AMER ABRA cE-Bs by e-International Publishing House, Ltd., UK. This is an open access article under the CC BYNC-ND license (http://creativecommons.org/licenses/by-nc-nd/4.0/). Peer-review under responsibility of AMER (Association of Malaysian Environment-Behaviour Researchers), ABRA (Association of Behavioural Researchers on Asians) and cE-Bs (Centre for Environment-Behaviour Studies), Faculty of Architecture, Planning \& Surveying, Universiti Teknologi MARA, Malaysia. DOI: https://doi.org/10.21834/e-bpj.v4i12.1902 
One of the ways of the intervention to reduce depression among the elderly with Alzheimer's is reminiscence therapy. It is economical and free from risks or side effects. Reminiscence therapy is an organized process of systematically reflecting on one's life with a focus on re-evaluation, making a decision on conflicts from the past, finding the importance in one's life and assessing former adaptive coping responses (Chen, Li, \& Li, 2012). It usually uses aids of different sources such as photos, video, and music (Lök, Bademli \& SelçukTosun, 2018). The objective of reminiscence therapy is to share experiences among people and make them feel appreciated and stronger. Besides, it can increase self-esteem and reduce depression which can give them positive effects on their quality of life. It also helps to reduce negative emotions and create happiness for the elderly quickly.

Various previous studies have shown several positive outcomes of reminiscence therapy, such as mood changes (Chang \& Chien, 2017), life satisfaction, self- esteem, integrity and mental improvement (Moral, Terrero, Galan, \& Rodriguez, 2015). Therefore the reminiscence therapy in elderly with Alzheimer's, increased depression level, reduction in cognitive functions as well as the quality of life, has been planned to be added in practices towards elderly at institutional home care because it is cost-effective and easy to conduct. Based on this target, this study aims to investigate the effect of individualized reminiscence therapy on depression levels among the elderly with Alzheimer's disease.

\subsection{Literature review}

Depression nowadays becomes a public health problem among the elderly. Depression can cause many adverse effects on the elderly with Alzheimer's disease such as social isolation and low self-esteem. It is also can further lead to mortality and even suicide. Depression generally can be defined as feeling sad, discouraged, or unhappy. In clinical definition, depression is a psychiatric disorder which require more than five depressive symptoms which are depressed mood or loss of interest or pleasure along with at least four other depressive symptoms including significant weight loss, sleep disturbance, psychomotor agitation or retardation, fatigue or loss of energy, feelings of worthlessness or excessive guilt, diminished ability to think or concentrate, and recurrent thoughts of death (Blumenthal, Smith \& Hoffman, 2012).

There is a relationship between depression and Alzheimer's disease among the elderly. Studies showed that depression is one of the risk factors of Alzheimer's disease. An elderly who had a history of depression are easy to have Alzheimer's disease at a rapid rate compared to non-depression (Ownby, Crocco, Acevedo, John, \& Loewenstein, 2006). If the depression symptom persists in a long time, it may lead to reduce in hippocampal volume and lead to cellular ageing (Mirza et al., 2016). Also, depression in the elderly with Alzheimer's can be related to the discrepancy of monoamines which to describe the occurrence of depression in Alzheimer's disease (Modrego, 2010). The cause of depression among them might have several factors. The factors of depression including old age, female, being a widower or single, low education status, presence of physical illness, using of multiple drugs, the existence of psychosocial stressors and the changes of white matter in the brain (Sözeri-varma, 2012).

\subsection{Method}

This exploratory study adopted a quasi-experimental pre-test and post-test design. The participants of the institutional home centre (Rumah Seri Kenangan Cheras) in Selangor were selected to take part in the study from April 2019 to June 2019. All the residents in the home centre were selected to participate in the study based on the following inclusion criteria: aged 60 years and above whom are medically-confirmed Alzheimer's disease and experienced Alzheimer's disease (based on the Montreal Cognitive Assessment, MoCA <26) patients, able to understand and communicate in English or Malay, possess good vision and hearing (Include if the participant using spectacles and hearing aids) and with depression symptoms. After a screening assessment, 32 participants met the inclusion criteria of this study.

Participants were group into two different groups, namely the reminiscence group and control group. Each of the members of the reminiscence group $(n=16)$ asked to complete the questionnaire (Cornell Scale for Depression) immediately after their decision to participate in the study which was seven days earlier before the commencement of the reminiscence therapy (pre-test). Participants in the control group $(n=16)$ asked to complete the same questionnaire after their decision to participate in the study (pre-test). Reminiscence therapy was planned for six weeks which is one week after all the selected participants decided to join in the study. Both groups (reminiscence and control group) completed the therapy in a six-week intervention period (post-test). All participants from both groups completed all the questionnaires at the same time.

\subsection{Intervention}

An individual reminiscence therapy used as a treatment in the intervention group. Each participant participated in six sessions of individual reminiscence therapy. The therapy held for six consecutive weeks with one session per week, which lasted for 40-60 minutes. Reminiscence therapy topic were chosen based on recommendations by Siverova and Buzgova (2018). In each session, the participants will call to mind their memories of a specific topic: 1. the place where I come from during childhood; 2. favourite activities and games during childhood; 3. school years, teachers, schoolmates, and friends; 4. first loves, first dating, early marriage, memorable anniversary; 5. favourite meals and dinings; 6 . holiday or festivities such as Hari Raya, Chinese New Year and Deepavali and discuss the food during all the celebrations. All sessions were conducted by the same therapist (a Master student in physiotherapy).

In the first meet up, each participant was greeted and made acquainted with each other, following the steps of the meeting as explained in the study by Siverová and Bužgová (2018). Each participant was informed of the confidentiality of all the meetings and interactions. At the beginning of each session, the therapist presented the topic and asked the participants to interactively share their memories and stories regarding past events or experiences. The therapist supported and responded to individual requests. 
Reminiscence objects such as photo, video, music, and foods were used as a trigger to help the individual to reminisce and share their story. The therapist also provided refreshments such as cookies, bread, and water. When the time of the therapy ended, the therapist closed the session through a summarized topic based on the topic for each week. Then, the topic would be presented in the following week and the therapist closes with a 'see you next week' statement to the participants.

The control group, on the other hand, was subjected to proper care as per their normal activity or daily living in the institutional home care without any specific intervention prescribed to the participants. They followed the regular care and activities provided by the home care itself.

\subsection{Instruments}

Several questionnaires are used to measure general characteristics (age, gender, education level, and marital status), mental status (Montreal Cognitive Assessment) and depression level (Cornell Scale for Depression).

Ziad Nasreddine developed The Montreal Cognitive Assessment (MoCA) in Montreal in 1996. It was designed as a rapid screening instrument for mild cognitive impairment. It consists of different cognitive domains which are attention and concentration, executive functions, memory, language, conceptual thinking, calculations, and orientation. The period to run the MoCA was estimated for around 10 minutes. The total score is 30 points. The count of 26 or above is considered healthy while, below 26 is abnormal.

Alexopoulos, Abrams, Young, and Shamonian developed the Cornell Scale for Depression in Dementia (CSDD). It is a 19-item scale used to measure depression among the elderly with dementia. The questionnaire evaluated the mood-related findings, physical findings, behavioural changes, cyclic functions, and cognitive changes in an individual. The scale is administered by the researcher in a semistructured interview format to the patients and caregivers independently. Each question is scored on a two-point scale: $0=a b s e n t ; 1=$ mild or intermittent; 2 = severe; $n / a=$ unable to evaluate. It takes 5 to 10 minutes to administer the questionnaire.

\subsection{Statistical Analysis}

The analytical analysis was analyzed by using SPSS version 22.0. The researchers used descriptive statistical tools, including numbers, percentages, means, and standard deviation. The one-way repeated measures ANOVA test was used to compare the three times mean scores of the intervention and the control group.

\subsection{Ethical considerations}

The endorsement of this study gained from the UiTM Research Ethics Committee (Reference No. 600-IRMI (5/1/6) and Jabatan Kebajikan Masyarakat (JKMM 100/12/5/2: 2018/418). All the elderly were told about the study objectives, and had their consent. They were also informed that their involvement in the study was voluntary and that they were fully capable of making their own decisions as well as not subjected to any guardianship law. They were able to understand all the rules in this study and have the right to withdraw from this study.

\subsection{Findings}

There is a difference in data from the participants for both groups regarding their socio-demographic characteristics (reminiscence and control). Table 1 shows the results related to the socio-demographic characteristics of the participants in the reminiscence and control group.

The majority of the participants in the reminiscence group are female (62.5\%), and the primary education level (50.0\%) is the highest in this group. In contrast, the majority in the control group is male (62.5\%) and with secondary education level (50.0\%).

Table 1. The socio-demographic characteristics of the participants in the reminiscence group and the control group

\begin{tabular}{|c|c|c|c|c|}
\hline \multirow[t]{2}{*}{ Social-demographic characteristic } & \multicolumn{2}{|c|}{ Reminiscence group ( $\mathrm{n}=16$ ) } & \multicolumn{2}{|c|}{ Control group $(n=16)$} \\
\hline & $\mathrm{n}$ & $\%$ & $\mathrm{n}$ & $\%$ \\
\hline \multicolumn{5}{|l|}{ Gender } \\
\hline Male & 6 & 37.5 & 10 & 62.5 \\
\hline Female & 10 & 62.5 & 6 & 37.5 \\
\hline \multicolumn{5}{|l|}{ Educational level } \\
\hline None & 1 & 6.25 & 1 & 6.25 \\
\hline Primary & 8 & 50.00 & 7 & 43.75 \\
\hline Secondary & 5 & 31.25 & 8 & 50.00 \\
\hline Tertiary & 2 & 12.50 & 0 & 0.00 \\
\hline
\end{tabular}

The effect of reminiscence therapy on depression levels among the elderly with Alzheimer's was assessed. The results gained from the study support the present opinion that reminiscence therapy has a significant effect on depression levels in the elderly. The result has a positive impact that supports previous evidence which reported that reminiscence therapy reduces depression level in the elderly with Alzheimer's disease. 
The analysis which is a one way repeated measure ANOVA was used to compare the scores on Cornell Scale for Depression in Dementia in the reminiscence group on statistic test with at Time 1 (pre-intervention), Time 2 (following intervention) and Time 3 (postintervention). The mean and standard deviations are documented in Table 2. The result showed that there was a significant effect for time, Wilks' Lambda $=.39, F(2,14)-11,(p<0.005)$, multivariate eta squared $=.61$.

Table 2. The result of the Cornell Scale for Depression in Dementia scores in Reminiscence Group

\begin{tabular}{llll}
\hline Time period & $\mathrm{N}$ & Mean & Standard Deviation \\
\hline Time 1 (Pre-intervention) & 16 & 8.69 & 1.08 \\
Time 2 (Following intervention) & 16 & 8.00 & 0.90 \\
Time 3 (Post-intervention) & 16 & 6.75 & 1.24 \\
\hline
\end{tabular}

A one way repeated measure ANOVA was used to compare scores on Cornell Scale for Depression in Dementia in Control Group on statistic test with at Time 1 (pre-intervention), Time 2 (following intervention) and Time 3 (post-intervention). The mean and standard deviations are documented in Table 3 . The result showed that there was no significant effect for time, Wilks' Lambda $=.87, F(2,14)-1$, $p=0.383$, multivariate eta squared $=.13$.

Table 3. The result of the Cornell Scale for Depression in Dementia scores in Control Group

\begin{tabular}{llll}
\hline Time period & $\mathrm{N}$ & Mean & Standard Deviation \\
\hline Time 1 (Pre-intervention) & 16 & 8.56 & 0.81 \\
Time 2 (Following intervention) & 16 & 8.38 & 0.62 \\
Time 3 (Post-intervention) & 16 & 8.50 & 0.97 \\
\hline
\end{tabular}

\subsection{Discussions}

The present results matched the findings in earlier studies which show that there are benefits of reminiscence therapy among the elderly with Alzheimer's disease. The result of the reminiscence therapy for the elderly with Alzheimer's disease indicated that a significant difference was found in the depression level between pre-intervention and post-intervention of the elderly with Alzheimer's disease $(p<0.005)$. Reminiscence therapy is a conservative and non-pharmacology treatment, and most of the studies of this intervention conducted in western countries. However, in Malaysia, there are still not enough studies on this. The cultural differences between Malaysia and other countries may affect the outcomes of reminiscence therapy. In a previous study, reminiscence therapy was recommended as an effective treatment for depression and shown to increase cognitive functions for the elderly with Alzheimer's disease (Duru Aşiret \& Kapucu, 2016). The previous meta-analysis also revealed that reminiscence therapy is recommended to reduce depressive symptoms and can help to improve the quality of life in the elderly with dementia (Park, Lee, Yang, Song \& Hong, 2019). Besides, it can enhance the level of confidence about the elderly's past life (Hsieh et al., 2010). It was believed that reminiscing about happy events can increase positive feelings and reduce the release of stress hormones which is cortisol in an individual (Speer \& Mauricio, 2017). It also provides a sense of pleasure and a pleasant atmosphere for the individuals. Thus, reminiscence therapy has a good outcome not only on depression levels but also on cognitive function and quality of life in the older adults with Alzheimer's disease. Besides that, reminiscence therapy helps increase communication and social activity among elderly people. This is because of the interaction between a person and another person that could help them reduce their psychological burden and release stress after reminiscing the positive events which engage the neural circuit, especially at striatum, which to enhance the positive mood (Speer \& Mauricio, 2017) and happiness (Jonsdottir, Jonsdottir, Steingrimsdottir, \& Tryggvadottir, 2001). Reminiscence also helps to minimize social isolation among the elderly with Alzheimer's. This finding is in agreement with Chang and Chien (2018) in their pilot study which showed that their interactions with the therapist were better after three weeks, and they were more responsive during the activity given in the intervention indicated in the increase of the degree of participation. Moreover, reminiscence therapy can improve self-esteem among the elderly (Maslakpak, 2013). This is supported by a study by Moral and colleagues (2015) on how reminiscence improves integrity, self-confidence, and life satisfaction towards the elderly in nursing home care. Together, these studies outline that all the positive effects of memory can help in managing the meaning of life and have a great experience during ageing itself.

Depression among the elderly can cause many adverse effects such, as loneliness, reduced physical activity as well as an increased healthcare cost, suicide, and mortality. All of these problems can burden society and countries. In contrast, some studies revealed that there was no beneficial effect of reminiscence therapy on depression level. Decrease in depressive symptoms might be due to external factors such as the individual ability to express and speak without being criticized as well as make time to talk to the participants regularly (Chao et al., 2006). Besides, the inconsistency in reminiscence result cause by external factors such as the regularity of the therapy given, the satisfaction of reminiscence and regrets, and psychological health (Hsieh et al., 2010). It is crucial to differentiate reminiscence as spontaneous or a general activity as it can induce psychological health. According to McKee and colleagues (2005), they argue that reminiscence not assessed because the elderly might not get the benefits of the therapy as involves talking about past experiences which might be harmful and can affect the elderly's mood and well-being. In their review, they also suggested that reminiscence must be better understood and the amount of general activity that elderly engage in should be assess to investigate whether different types of memory enhance well-being or improve quality of life or not.

In closing, this study has several limitations. First, the quasi-experimental study was used (non-randomized). The intervention needs more improvement and need investigate in a randomized, controlled trial with a more differentiated and significant sample. Secondly, this study does not involve any other interventions. So, it needs to be more combined with treatment such as exercise or other non- 
pharmacologic to view the results. More variables can also include to see the effectiveness of the combined intervention itself. Thirdly, reminiscence therapy should be more precise, either by using live interviews, narrative or discussion.

\subsection{Conclusion and Recommendations}

In this study, it was revealed that reminiscence therapy can reduce the depression level among the elderly with Alzheimer's disease. Reminiscence can help them to boost their positive moods as they can share their feeling or thoughts from their previous life. It also helps them to communicate more and involve in their social life activities. An increase in depression level reported can get many adverse effects on them. Based on the study result, reminiscence therapy showed positively significant towards depression.

In conclusion, our results suggest that reminiscence therapy should be considered as a routine activity for home care to decrease depression and improve cognitive functions as well as the general quality of life of the elderly with Alzheimer's disease in institutional care. For further valuation, duplication of this study using larger samples selected from different communities and samples is recommend to confirm the significance of results. It is suggest to all other healthcare experts who are working with elderly patients with Alzheimer's to implement "reminiscence therapy," as part of routine care which can aid them to increase their level of quality of life in different settings.

\section{Acknowledgements}

This project was made possible by grants from the Research Management Institute (600-IRMI 5/3/GIP [039/2018], Universiti Teknologi MARA, Selangor, Malaysia, via the Research Intensive Faculty/Excellence Fund. The authors are grateful to the participants from the Rumah Seri Kenangan, Cheras, Selangor, Malaysia, for voluntary participation and cooperation through this research.

\section{References}

Chang, H. C., \& Chien, H. W. (2018). Effectiveness of group reminiscence therapy for people living with dementia in a daycare centers in Taiwan. Dementia, 17(7), 924935 .

Chen, T. ji, Li, H. jie, \& Li, J. (2012). The effects of reminiscence therapy on depressive symptoms of Chinese elderly: study protocol of a randomized controlled trial. BMC Psychiatry, 12(1), 1 .

Duru Aşiret, G., \& Kapucu, S. (2016). The Effect of Reminiscence Therapy on Cognition, Depression, and Activities of Daily Living for Patients with Alzheimer Disease. Journal of Geriatric Psychiatry and Neurology, 29(1), 31-37.

Hsieh, C. J., Chang, C., Su, S. F., Hsiao, Y. L., Shih, Y. W., Han, W. H., \& Lin, C. C. (2010). Reminiscence group therapy on depression and apathy in nursing home residents with mild-to-moderate dementia. Journal of Experimental and Clinical Medicine, 2(2), 72-78.

Jonsdottir, H., Jonsdottir, G., Steingrimsdottir, E., \& Tryggvadottir, B. (2001). Group reminiscence among people with end-stage chronic lung diseases. Journal of Advanced Nursing, 35(1), 79-87.

Juan C. Meléndez Moral, Flor B. Fortuna Terrero, Alicia Sales Galán \& Teresa Mayordomo Rodríguez (2015) Effect of integrative reminiscence therapy on depression, well-being, integrity, self-esteem, and life satisfaction in older adults. The Journal of Positive Psychology, 10:3, 240-247.

Kikuchi, T., Uchida, H., Suzuki, T., Watanabe, K., \& Kashima, H. (2011). Patients' attitudes toward side effects of antidepressants: An Internet survey. European Archives of Psychiatry and Clinical Neuroscience, 261(2), 103-109.

Lök, N., Bademli, K., \& Selçuk-Tosun, A. (2019). The effect of reminiscence therapy on cognitive functions, depression, and quality of life in Alzheimer patients: Randomized controlled trial. International Journal of Geriatric Psychiatry, 34(1), 47-53.

Maslakpak, H. (2013). The effect of reminiscence therapy on the self-esteem among residents of a nursing home in Uromie, 1(2).

McKee, K. J., Wilson, F., Chung, M. C., Hinchliff, S., Goudie, F., Elford, H., \& Mitchell, C. (2005). Reminiscence, regrets and activity in older people in residential care: Associations with psychological health. British Journal of Clinical Psychology, 44(4), 543-561.

Meléndez, J. C., Fortuna, F. B., Sales, A., \& Mayordomo, T. (2015). Effect of integrative reminiscence therapy on depression, well-being, integrity , self-esteem , and life satisfaction in older adults, 10(3), 240-247.

Modrego, P. J. (2010). Depression in Alzheimer's Disease . Pathophysiology , Diagnosis , and Treatment, 21, 1077-1087.

Nuri, T. H. M., Hong, Y. H., Ming, L. C., Joffry, S. M., Othman, M. F., \& Neoh, C. F. (2017). Knowledge on Alzheimer's disease among public hospitals and health clinics pharmacists in the State of Selangor, Malaysia. Frontiers in Pharmacology, 8(OCT), 1-6.

Ownby, R. L.; Crocco, E.; Acevedo, A.; John, V.; Loewenstein, D. (2006). Depression and risk for Alzheimer disease: systematic review, meta-analysis, and metaregression analysis. Arch Gen Psychiatry, 63(5), 530-538.

Sharif, F., Mansouri, A., Jahanbin, I., \& Zare, N. (2018). Effect of group reminiscence therapy on depression in older adults attending a day centre in Shiraz, southern Islamic Republic of Iran. Eastern Mediterranean Health Journal, 16(7), 765-770.

Siverová, J., \& Bužgová, R. (2018). The effect of reminiscence therapy on quality of life, attitudes to ageing, and depressive symptoms in institutionalized elderly adults with cognitive impairment: A quasi-experimental study. International Journal of Mental Health Nursing, 27(5), 1430-1439. 
Sözeri-varma, G. (2012). Depression in the Elderly : Clinical Features and Risk Factors, 3(6), 465-471.

Speer, M. E., \& Mauricio, R. (2017). Reminiscing about positive memories buffers acute stress responses. Nature Human Behaviour, 1(5), 1-9.

Wu, L. F. (2011). Group integrative reminiscence therapy on self-esteem, life satisfaction and depressive symptoms in institutionalised older veterans. Journal of Clinical Nursing, 20(15-16), 2195-2203. 